\title{
Ambient thermal comfort analysis for four major cities in Thailand, Cambodia, and Laos: Variability, trend, factor attribution, and large-scale climatic influence
}

\author{
Kimhong Chea ${ }^{\mathrm{a}, \mathrm{b}}$, Kasemsan Manomaiphiboon ${ }^{\mathrm{a}, \mathrm{b}, *}$, Nishit Aman ${ }^{\mathrm{a}, \mathrm{b}}$, Sirichai Thepa ${ }^{\mathrm{c}}$, \\ Agapol Junpen $^{\mathrm{a}, \mathrm{b}}$, Bikash Devkota ${ }^{\mathrm{a}, \mathrm{b}}$ \\ a The Joint Graduate School of Energy and Environment, King Mongkut's University of Technology \\ Thonburi, Bangkok 10140 Thailand \\ b Center of Excellence on Energy Technology and Environment, Ministry of Higher Education, Science, \\ Research and Innovation, Bangkok 10400 Thailand \\ c School of Energy, Environment and Materials, King Mongkut's University of Technology Thonburi, \\ Bangkok 10140 Thailand
}

*Corresponding author, e-mail: kasemsan.jgsee@gmail.com

Received 26 Nov 2020

Accepted 14 Apr 2021

\begin{abstract}
Characterizion of ambient thermal comfort using a standard heat index (HI) was performed for Bangkok, Chiang Mai, Phnom Penh, and Vientiane, with data covering 37 and 17 years for the first two and last two cities, respectively. HI was lower during the night and the early morning but high in the afternoon in both the dry and the wet seasons. Its diurnality showed a tendency to be more influenced by temperature than by relative humidity. The daily maximum heat index (DMHI) was the highest in April-May due to both warm and humid conditions, but was the lowest in December-January due to cool dry air. Among the five considered risk DMHI levels, "extreme caution" occurred the most often for the majority of the months, and "danger" occurrence tended to increase in April-June. Low-latitude cities (i.e., Bangkok and Phnom Penh) showed less pronounced diurnality and seasonality due to their proximity to the Equator and large water bodies. Increasing trends in seasonal DMHI average were found in Bangkok, Chiang Mai, and Vientiane; while decreasing trends in Phnom Penh were found in both seasons. The trends in seasonal DMHI extremes were consistent with those of the seasonal DMHI average in terms of direction (except Bangkok). Polynomial regression modeling, developed for trend factor attribution, suggests more influence of humidity than of temperature for most trends. Partial correlation analysis indicates seasonal DMHI average to be more associated with El Niño-Southern Oscillation than with the Indian Ocean Dipole.
\end{abstract}

KEYWORDS: urban climate, heat index, extreme condition, Nino3.4, dipole mode index

\section{INTRODUCTION}

Ambient thermal comfort (hereafter, "thermal comfort") is a measure of how humans feel under certain environmental conditions outdoors, and it is typically regulated by both temperature and humidity in ambient air $[1,2]$. Human body functions on the principle of thermal homeostasis, which provides natural resistance and helps keep body temperature constant under certain limits. Under warm conditions, the human body sweats, which removes heat from the skin through evaporation, in turn taking away heat and producing a cooling sensation. Under humid conditions, the evaporation rate decreases, and heat removal becomes slower, causing thermal discomfort [3]. Prolonged exposure to heat strain may have several negative effects, e.g., fatigue and irritability, heat cramps and exhaustion, and even heat stroke [4]. A large or well-developed city is generally associated with urban heat islands, a phenomenon with outdoor temperature in its center (i.e., urban core) being larger than that in its surroundings due to modified land cover and built-up materials, emitting anthropogenic heat $[5,6]$. Such factors could also modify surface moisture and then humidity [6]. Accordingly, thermal comfort is an important subject for built-environment/urban planning [7] and labor-related work productivity [8].

A number of indices or measures were proposed to quantify the thermal comfort $[1,2]$, one of which was the heat index (HI). It was adopted in this study given its direct robust calculation us- 
ing temperature ( $\mathrm{T}$ ) and relative humidity ( $\mathrm{RH})$, and its extensive use in various cities or regions. Increasing trends in $\mathrm{HI}$ in recent decades and $\mathrm{El}$ Niño-Southern Oscillation (ENSO) effects on extreme events over Mesoamerica and the Caribbean Sea were reported [3]. A long-term climatological study of HI was conducted for the Southern United States [9], while another study in the city of Knoxville (US) found the potential of trees to help decrease excess urban heat, in turn increasing humidity [10]. Trends in population exposure to thermal stress using several indices (including HI) in eight European cities were examined [11]. For India, a study on seven urban centers in the western coastal area reported an increasing trend in a number of indices [12]. In the context of climate change, a study projected changes in $\mathrm{HI}$ over different global regions using output from a global climate model [13].

For Thailand and Upper Southeast Asia (or Indochina), the applicability of $\mathrm{HI}$ for Thailand was examined [14]. A study in Central Thailand considered two indices, HI and wet-bulb globe temperature, for outdoor and indoor heat exposures of workers at selected industrial sites [15]. Another study in Da Nang, Vietnam projected HI trends until the mid-21st century using results on the basis of six global climate models under two future scenarios [16]. The linkage between $\mathrm{HI}$ and heatrelated illness in Thailand, pointing to the potential usefulness of a heat warning system if available, was also reported [17]. A study in Chiang Mai, Northern Thailand used short-term weather data to explore certain HI characteristics [18], while another study in the same city used physiologically equivalent temperature as an alternative to $\mathrm{HI}$ and proposed thermally acceptable ranges for outdoor and semi-outdoor spaces [19]. Based on a long-term climatological study of $\mathrm{HI}$ over recent decades, an increase in $\mathrm{HI}$ over most stations in Thailand was reported [20].

Several aspects related to thermal comfort still require further scientific investigation in Upper Southeast Asia, e.g., the HI variability in multiple cities or at different spatial scales and different time scales, and the role of important large-scale climatic modes. Moreover, given the dependence of HI on both temperature and humidity, how a trend in $\mathrm{HI}$ is accounted for by them is of essential interest. These were the motivational bases of our present analysis for four major cities in three Southeast Asian countries, namely Bangkok (BK) of Thailand, Chiang Mai (CM) of Thailand, Phnom Penh (PP) of Cambodia, and Vientiane (VT) of Laos (Fig. S1). To our knowledge and from a literature survey, this study was also the first effort to assess outdoor thermal comfort in the latter two cities.

\section{MATERIALS AND METHODS}

\section{Study areas}

"City" here is defined as a central populated area with a high degree of urbanization and business activities. The World Urbanization Prospects 2018 under the United Nations (https://population.un. org/wup/, accessed on 5 March 2020) also indicates each of these cities as urban agglomeration. Bangkok is the capital of Thailand, situated in the lower central plain of Thailand with a large river (Chao Phraya) running through it, bordering the Gulf of Thailand to the south. Chiang Mai Province is in the Northern Region, with the city sitting in the middle of a mountainous valley. Among a total of 77 provinces, Bangkok and Chiang Mai rank the largest in economic development and urbanization in the Central and Northern Regions, respectively. Phnom Penh is the capital of Cambodia and designated as a municipality (equivalent to a province out of 25). It is situated in the southern central plain of Cambodia and surrounded by three large rivers: Tonle Sap, Bassac, and Mekong. Vientiane is a prefecture (equivalent to a province out of 18) and the capital of Laos, situated in a plain as a northern extension connected to the Korat Plateau of Thailand. The Mekong River is adjacent to the south, as the border between Laos and Thailand. In recent decades, each of the three countries apparently had overall positive growth in both population and economy (Fig. S2). The general climate of the four selected cities is under the influence of the two monsoons (i.e., northeast and southwest), like most of the Upper Southeast Asia [21]. The northeast and southwest monsoons are responsible for regional dry and wet seasons, respectively. In this study, the dry season was assigned in November-April, while the wet season was assigned in May-October. The concept of the seasonal year was applied throughout the analysis, starting in November of the previous year and ending in October of the year after. For example, seasonal year 2010 comprised the dry season of 2010 from November 2009 to April 2010, and the wet season of 2010 from May to October 2010.

\section{Data and methods}

Hourly temperature (T) and relative humidity (RH) data from standard weather stations in the four 
cities were obtained from the Thai Meteorological Department (TMD) and the National Centers for Environmental Information (NCEI, ftp://ftp.ncdc. noaa.gov/pub/data/noaa) (Table S1). The two variables are required to calculate HI. The reported data are typically quality-controlled by their responsible monitoring agencies, which are the TMD for Thailand, the Ministry of Water Resources and Meteorology (MoWRAM) for Cambodia, and the Department of Meteorology and Hydrology (DMH) for Laos. For BK and CM, the data span from November 1980 to October 2017 (1981-2017 as seasonal years, or 37 years) and are available for all hours (1-24 LT or local hours). For PP and VT, the data are limited to only from November 2000 to October 2017 (2001-2017 as seasonal years or 17 years) with missing data substantially observed before 2001 and only daytime hours reported. Thus, the used daytime hours here are 7-18 LT for BK, CM, and PP, but 7-17 LT for VT (i.e., no observations made after 17 LT). The obtained data were further quality-checked as follows: (a) validity within a suitable range $\left(-5^{\circ} \mathrm{C}\right.$ to $50^{\circ} \mathrm{C}$ for $\mathrm{T}$, and 0 $100 \%$ for $\mathrm{RH}$ ) and (b) single-station homogeneity test. Any violations were excluded as missing. In the NCEI database, the dew-point temperature is given. $\mathrm{RH}$ was computed using the basic ClausiusClapeyron relationship. Hourly surface air pressure (P) from the Global Land Data Assimilation System (GLDAS) [22] (https://giovanni.gsfc.nasa.gov, accessed on 5 March 2020) was also used to assist the calculation of specific humidity (SH), which was used later in trend factor attribution. The percentages of missing data of the final $\mathrm{T}$ and $\mathrm{RH}$ were found to be small, i.e., $6.9 \%$ and $7.1 \%$ for Bangkok, $5.3 \%$ and $5.5 \%$ for Chiang Mai, $3.7 \%$ and $3.8 \%$ for Phnom Penh, and 6.8\% and 6.9\% for Vientiane. In any statistical calculations, at least $50 \%$ of nonmissing values in a pooled sample were required.

The general climate of the four selected cities (BK, CM, PP, and VT) is like most of the Upper Southeast Asia, which is mainly under the influence of the two southwest and northeast monsoons. The former monsoon brings warm humid air from the Indian Ocean and in turn precipitation, (i.e., the wet season), which approximately lasts from May to October. The latter monsoon lasts from November to February, bringing cool dry air from the mainland China and the East Asia. The area background of each weather station within a $2-\mathrm{km}$ radius was visually inspected using recent satellite images from Google Earth (Fig. S3) $[5,23]$. Both BK and PP lie in a low-level plain at low latitudes $\left(11^{\circ}-14^{\circ}\right)$. CM and VT lie in a highland at relatively high latitudes $\left(17^{\circ}-19^{\circ}\right)$. BK and PP, thus, have relatively lower temperature than other cities. The transitional period of the monsoons in March-April is a summer with relatively warm weather. BK, CM, PP, and VT stations are about $20,2,8$, and $3 \mathrm{~km}$ from their respective innermost city cores, respectively. For VT, Mekong River is in its proximity to the south. In our preliminary analysis, dry-season daytime-based diurnal temperature range (DTR) was also examined for each city since its long-term negative trend might be induced by urbanization [24], and DTR trends in BK and CM were found to be significantly negative (at a 0.05 level) with no significant DTR trends found in PP and VT, suggesting the relatively rapid degree of urbanization for $\mathrm{BK}$ and $\mathrm{CM}$.

In this study, linear least-squares fitting was employed for trend estimation on a yearly time series, with the slope of a fit assigned as trend. To determine the trend significance against the null hypothesis of no trend, a non-parametric Mann-Kendall test was used, that had been applied in climate-related studies [12,21,25]. A block bootstrapping technique $[25,26]$ was coupled with the significance test to account for serial correlation in a time series. A homogeneity test of temperature observed at each individual weather station was also performed. A time series of a climate variable is said to be homogeneous when its variation is mainly caused by climatic conditions and not others (e.g., changes in instrumentation, monitoring method, and local environment). Here, a single-series change point detection (CPD) technique [27,28], with a MannWhitney nonparametric test, was applied. If any abrupt change at a time in data distribution is significantly found or detected, the series is regarded as inhomogeneous. In this study, a time series was formed by monthly average values over the full period of data and then de-trended to enhance abrupt changes or effects, i.e., reducing any potential gradual or slow effects (e.g., changes in local environment and climate). No station has significant (at a 0.05 level) change point, having adequate homogeneity for use in the study. HI calculation follows the algorithm by the US National Weather Service (NWS) $[1,4]$, which is based on Steadman's original framework and later modifications [1,29-31] as shown in Fig. S4. The daily daytime maximum heat index (DMHI) was adopted here to represent highend daily exposure given that $\mathrm{HI}$ tends to intensify during the daytime. Some previous studies also adopted DMHI in investigations [3, 32, 33]. For any of the other weather variables, their daily value on 
a particular day corresponds to the time at which DMHI registered on that day. The availability of $\mathrm{T}$ and RH data to compute DMHI, was high ( $>90 \%$ of total records) for every station and each dry or/wet season (Table S1).

\section{RESULTS AND DISCUSSION}

\section{Temporal variability}

The diurnal variation in HI (in terms of mean) showed a similar pattern for all the cities, being relatively low during nighttime and early morning but increasing during daytime due to surface solar heating (Fig. 1). HI peaked at 13-16 LT and was the lowest at 6-7 LT. During these morning hours, although minimal $\mathrm{T}$ and maximal $\mathrm{RH}$ occurred (Fig. 1), HI was more dependent on or sensitive to $\mathrm{T}$ than $\mathrm{RH}$, as suggested by the coefficients in the top equation of the NWS algorithm. Peak HI tended to correspond to maximal $\mathrm{T}$ and minimal $\mathrm{RH}$ in most cases. For DMHI, occurrence was most often seen in the early-to-mid afternoon. Its frequency distribution was more dispersed or flatter in the wet season than in the dry season, possibly due to local weather conditions on the surface level being attenuated by precipitation. The degree of diurnal variation (or diurnality) was assessed using the diurnality index (DI) as defined in Eq. (1):

$$
\mathrm{DI}_{\mathrm{day}}=\frac{1}{11 \bar{q}} \sum_{i=1}^{11}\left|q_{i}-\bar{q}\right|,
$$

where $q_{i}$ is the quantity pertaining to calendar month $i(7,8,9, \ldots, 17)$, and $\bar{q}$ is the average over 7-17 LT for all the cities. DI over $11 \mathrm{~h}$ theoretically ranged between 0 and 1.818 (the larger value, the stronger diurnal variation). In the annual cycle of DMHI, all four cities showed patterns similar to those found in $\mathrm{T}$ in terms of monthly mean (Fig. 2). DMHI peaked in April-May, but T was always the highest in April. Increased RH in May, which is the onset of the southwest monsoon or the wet season, explains DMHI being as high as in April, even though lower T occurred in May. DMHI was the lowest in December-January, the peak time (coolest and driest) of the northwest monsoon or the dry season. We then looked further to the top five values (not shown) among all cities in each season, ranging $55^{\circ} \mathrm{C}-60^{\circ} \mathrm{C}$ in the dry season and $61^{\circ} \mathrm{C}-72^{\circ} \mathrm{C}$ in the wet season. All of these extreme values were associated with warm and quite humid conditions ( $\mathrm{T}=35^{\circ} \mathrm{C}-39^{\circ} \mathrm{C}$ and $\left.\mathrm{RH}=60 \%-100 \%\right)$. The highest DMHI $\left(72^{\circ} \mathrm{C}\right)$ was found in BK in August 1996 with $\mathrm{T}=35^{\circ} \mathrm{C}$ and $\mathrm{RH}=100 \%$. The degree of monthly variation was assessed by the seasonality index (SI) as defined in Eq. (2) [34]:

$$
\mathrm{SI}=\frac{1}{12 \bar{q}} \sum_{i=1}^{12}\left|q_{i}-\bar{q}\right|
$$

where $q_{i}$ is the quantity pertaining to calendar month $i(1,2,3, \ldots, 12)$, and $\bar{q}$ is the average over the 12 calendar months. SI over 12 months theoretically ranged between 0 and 1.833 (the larger the value, the stronger the seasonality). Here, the high-latitude cities (CM and VT) showed obviously stronger HI diurnality (Fig. 1). For the seasonality of DMHI, T, and RH, both cities also showed an equal or stronger degree (Fig. 2), potentially attributed to their geographical locations.

For health risk, the classification of thermal comfort into levels is useful for indicating the danger or harm of heat that can affect a human body, especially with intense or prolonged exposure and/or physical activity. Prolonged exposure to heat can cause heat exhaustion, while frequent exposure may cause heat stroke $[4,16]$. Five health-risk levels were used: (1) normal $\left(<27^{\circ} \mathrm{C}\right)$, (2) caution $\left(27^{\circ} \mathrm{C}-32^{\circ} \mathrm{C}\right)$, (3) extreme caution $\left(32^{\circ} \mathrm{C}-41^{\circ} \mathrm{C}\right)$, (4) danger $\left(41^{\circ} \mathrm{C}-54^{\circ} \mathrm{C}\right)$, and (5) extreme danger $\left(\geqslant 54^{\circ} \mathrm{C}\right)[14,20]$. Fig. 2 shows how frequent these levels registered in each calendar month were. As seen in all cities, the "extreme caution" tended to dominate for most of the year. The occurrence of the "danger" level increased during the summer and early wet-season months (April-June). Lowlatitude cities (BK and PP) tend to experience this level more often possibly due to being highly urbanized and populated, likely urban heat island effects, and being located in low latitudes closer to the equator, the Indian Ocean, and the Gulf of Thailand as major moisture sources.

\section{Trend estimation and factor attribution}

The trend estimation of DMHI was performed by season for each city using linear regression with the non-parametric Mann-Kendall test for trend significance, as stated previously. Attributing a DHMI trend to $\mathrm{T}$ and $\mathrm{RH}$ offers more insight than trend information alone does. Doing so is not a straightforward task due to the nonlinear relationship between $\mathrm{HI}$ and those two factors. A statistical technique was developed here to facilitate the factor attribution of trend, which is to linearize DMHI as expressed by 
(a) Diurnal variation in BK
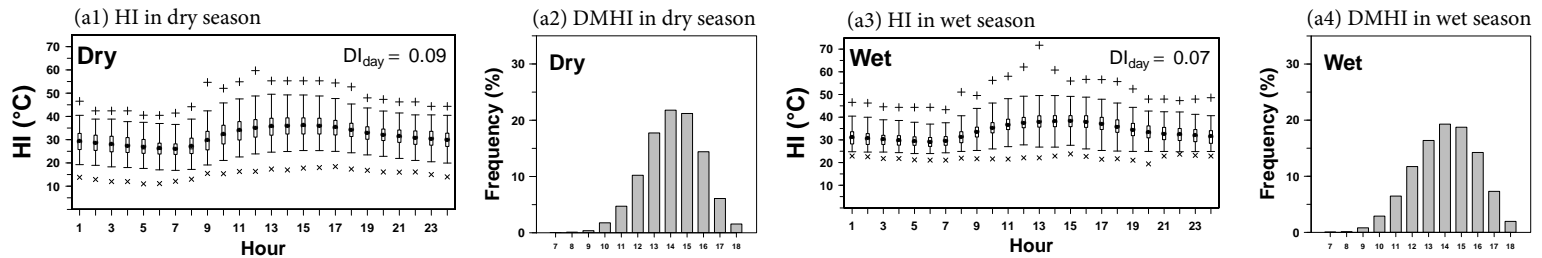

(b) Diurnal variation in CM
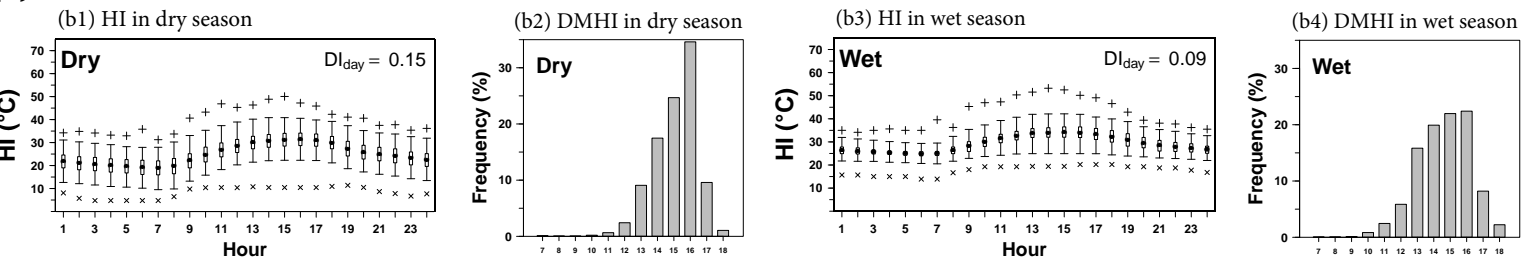

(c) Diurnal variation in PP
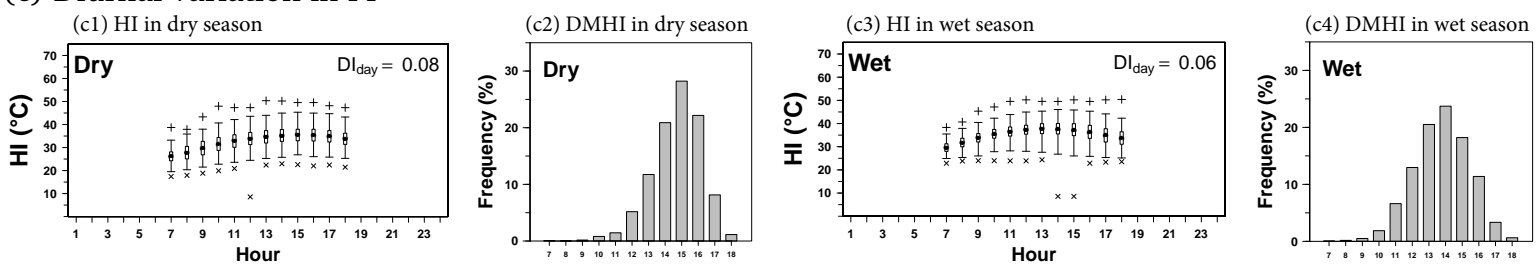

(d) Diurnal variation in VT
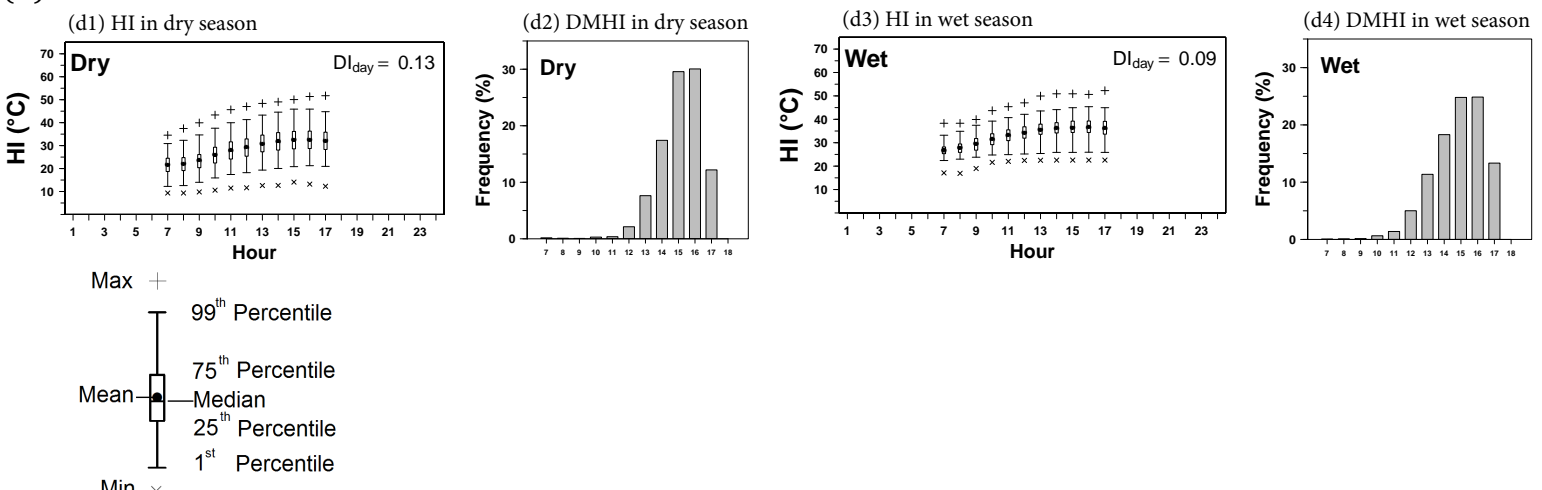

Fig. 1 Climatological diurnal variation of HI and DMHI occurrence (\% of total non-missing values) at each hour of day by season of the 4 cities: (a) BK, (b) CM, (c) PP, and (d) VT. $x$-axis represents local hour. $\mathrm{DI}_{\text {day }}$ is daytime (7-17 LT) diurnality index.

the second-order polynomial regression model (3):

$$
\begin{aligned}
\mathrm{DMHI}_{\mathrm{m}}= & a_{0}+a_{1} \mathrm{~T}+a_{2} \mathrm{SH}+a_{3} \mathrm{P}+a_{4} \mathrm{~T}^{2}+a_{5} \mathrm{SH}^{2} \\
& +a_{6} \mathrm{P}^{2}+a_{7} \mathrm{~T} \cdot \mathrm{SH}+a_{8} \mathrm{~T} \cdot \mathrm{P}+a_{9} \mathrm{SH} \cdot \mathrm{P},
\end{aligned}
$$

where $\mathrm{DMHI}_{\mathrm{m}}$ is the modeled DMHI $\left({ }^{\circ} \mathrm{C}\right)$, $\mathrm{T}$ is the temperature $\left({ }^{\circ} \mathrm{C}\right), \mathrm{SH}$ is the specific humidity $(\mathrm{kg} / \mathrm{kg}$ or none), $\mathrm{P}$ is the surface pressure ( $\mathrm{Pa}), a_{0}$ is the intercept, and $a_{i}$ is the regression coefficient of term $i$. Specific humidity is the mixing ratio of vapor mass to moist air mass), which is advantageous to use since it does not have direct dependence on temperature as opposed to $\mathrm{RH}$. Its calculation was carried out using the "Humidity" package in R (package version 0.1.5, https://github.com/caijun/ humidity) that requires only $\mathrm{T}, \mathrm{RH}$, and $\mathrm{P}$ as input. To seek a parsimonious regression model, the range of each of the three variables in the data (pooled from all four stations) was determined and then uniformly divided into 20 values, resulting in 8000 $(20 \times 20 \times 20)$ combinations as the initial sets. After removing any unrealistic sets (i.e., giving $\mathrm{RH}>$ $100 \%$ ), as much as $71 \%$ of the initial sets was available to fit the model. The backward elimination for the regression terms was carried out stepwise, considering: (1) change in the adjusted coefficient 
(a) Monthly climatology in BK (a1) DMHI

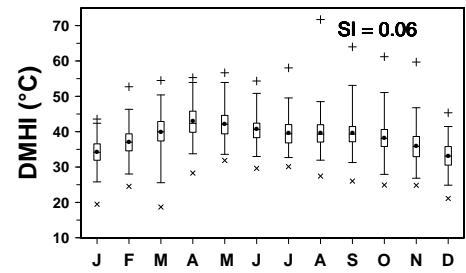

(b) Monthly climatology in CM (b1) DMHI

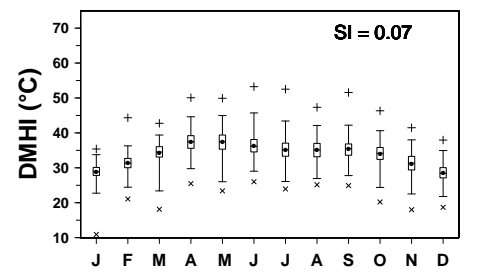

(c) Monthly climatology in PP (c1) DMHI

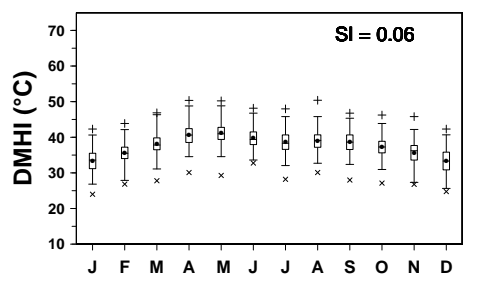

(d) Monthly climatological in VT (d1) DMHI

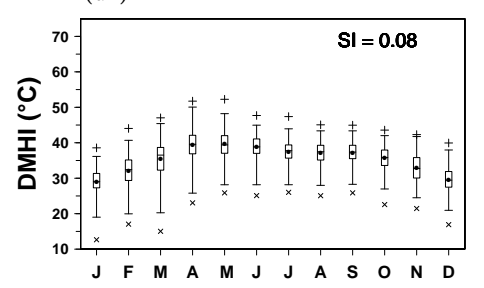

$\operatorname{Max}+$

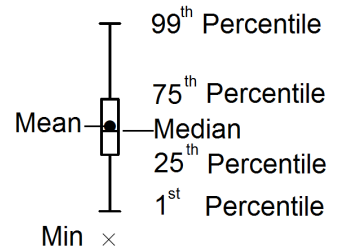

(a2) Average $\mathrm{T}$ and $\mathrm{RH}$

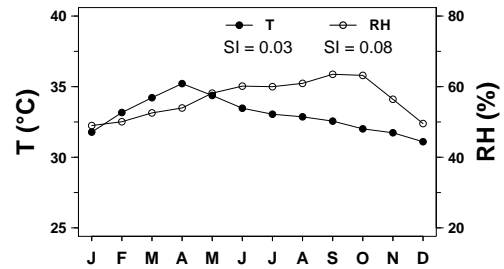

(b2) Average $\mathrm{T}$ and $\mathrm{RH}$

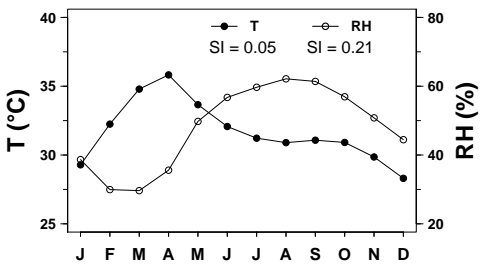

(c2) Average $\mathrm{T}$ and $\mathrm{RH}$

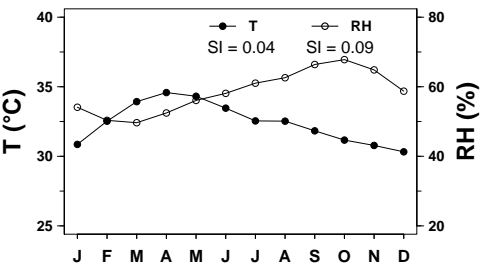

(d2) Average T and RH
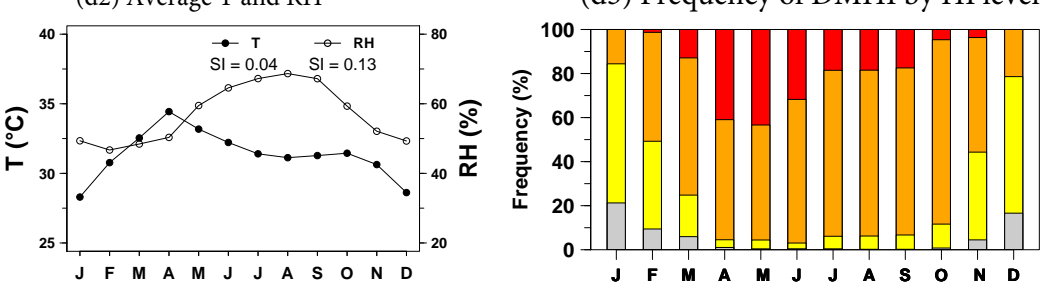

(a3) Frequency of DMHI by HI level

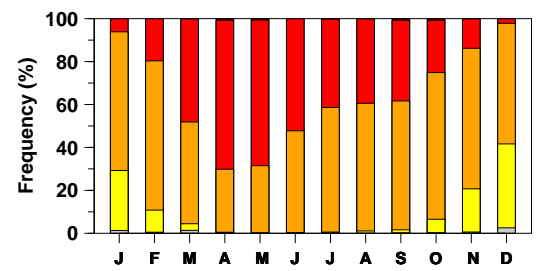

(b3) Frequency of DMHI by HI level

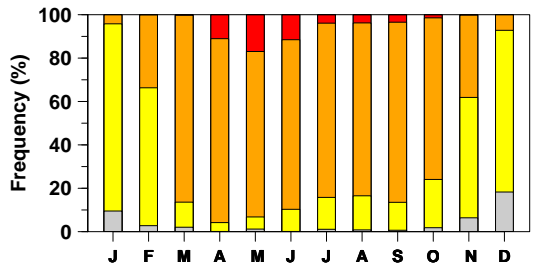

(c3) Frequency of DMHI by HI level

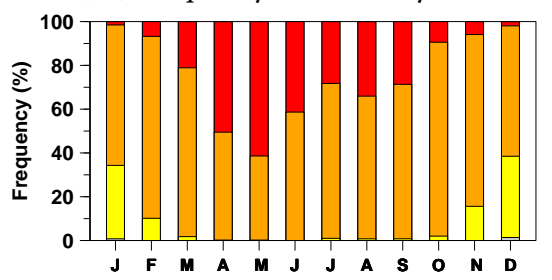

(d3) Frequency of DMHI by HI level

Normal $=$ Caution $\quad$ Extreme caution $\quad$ Danger - Extreme danger

Fig. 2 Climatological monthly DMHI (left), monthly average T and RH (middle), and monthly frequency of DMHI by HI level (right) of the 4 cities: (a) BK, (b) CM, (c) PP, and (d) VT. HI levels are "normal", "caution", "extreme caution", "danger", and "extreme danger". SI is seasonality index.

of determination $\left(R_{\text {adj }}^{2}\right)$ and (2) p-values of the regression coefficients in the elimination process.

The final parsimonious model had only $\mathrm{T}, \mathrm{SH}$, and $\mathrm{SH}^{2}$ as the remaining terms ( $p$-value $<0.01$, $R_{\mathrm{adj}}^{2}=0.99$ ), of which the corresponding coeffi- cients were $a_{0}=-3.061^{\circ} \mathrm{C}, a_{\mathrm{T}}=1.063, a_{\mathrm{SH}}=$ $-3.288 \times 10^{2}{ }^{\circ} \mathrm{C}$, and $a_{\mathrm{SH}^{2}}=3.523 \times 10^{4}{ }^{\circ} \mathrm{C}$. Its predictability, when compared against the original DMHI data, was satisfactory with a mean bias of $<0.1^{\circ} \mathrm{C}$ and a mean error of $1.2^{\circ} \mathrm{C}$. A mean bias 
Table 1 Trends in $\mathrm{DMHI}_{\mathrm{m}}$ and DMHI_T10 $\mathrm{m}$ and factor attribution by season.

\begin{tabular}{|c|c|c|c|c|c|}
\hline \multirow{3}{*}{ City } & \multirow{3}{*}{ Term } & \multicolumn{2}{|c|}{$\mathrm{DMHI}_{\mathrm{m}}$} & \multicolumn{2}{|c|}{ DMHI_T10 } \\
\hline & & Dry season & Wet season & Dry season & Wet season \\
\hline & & Trend $\left({ }^{\circ} \mathrm{C} \mathrm{dec}{ }^{-1}\right)$ & Trend $\left({ }^{\circ} \mathrm{C} \operatorname{dec}^{-1}\right)$ & Trend $\left({ }^{\circ} \mathrm{C} \operatorname{dec}^{-1}\right)$ & Trend $\left({ }^{\circ} \mathrm{C} \mathrm{dec}{ }^{-1}\right)$ \\
\hline \multirow{3}{*}{$\mathrm{BK}$} & $B_{\mathrm{m}}$ & 0.05 & 0.23 & -0.15 & -0.19 \\
\hline & $C_{\mathrm{T}}$ & $0.11(220.0 \%)$ & $0.15(65.2 \%)$ & $0.01(-6.7 \%)$ & $0.01(-5.3 \%)$ \\
\hline & $C_{\mathrm{SH}}$ & $-0.06(-120.0 \%)$ & $0.09(34.8 \%)$ & $-0.16(106.7 \%)$ & $-0.20(105.3 \%)$ \\
\hline \multirow{3}{*}{$\mathrm{CM}$} & $B_{\mathrm{m}}$ & 0.32 & 0.43 & 0.15 & 0.22 \\
\hline & $C_{\mathrm{T}}$ & $0.21(65.6 \%)$ & $0.15(34.9 \%)$ & $0.04(26.7 \%)$ & $0.35(159.1 \%)$ \\
\hline & $C_{\mathrm{SH}}$ & $0.11(34.4 \%)$ & $0.28(65.1 \%)$ & $0.11(73.3 \%)$ & $-0.13(-59.1 \%)$ \\
\hline \multirow{3}{*}{$\mathrm{PP}$} & $B_{\mathrm{m}}$ & $-1.37^{*}$ & -1.53 & $-2.94^{*}$ & -2.24 \\
\hline & $C_{\mathrm{T}}$ & $1.03(-75.2 \%)$ & $1.17(-76.1 \%)$ & $0.89(-30.3 \%)$ & $1.20(-53.6 \%)$ \\
\hline & $C_{\mathrm{SH}}$ & $-2.40(175.2 \%)$ & $-2.70(176.1 \%)$ & $-3.83(130.3 \%)$ & $-3.44(153.6 \%)$ \\
\hline \multirow{3}{*}{ VT } & $B_{\mathrm{m}}$ & $1.35^{\dagger}$ & $1.77^{*}$ & $2.18^{\dagger}$ & $2.63^{*}$ \\
\hline & $C_{\mathrm{T}}$ & $0.50(37.0 \%)$ & $0.79(44.6 \%)$ & $0.66(30.3 \%)$ & $1.25(47.5 \%)$ \\
\hline & $C_{\mathrm{SH}}$ & $0.85(63.0 \%)$ & $0.98(55.4 \%)$ & $1.52(69.7 \%)$ & $1.38(52.5 \%)$ \\
\hline
\end{tabular}

$C_{\mathrm{T}}=a_{\mathrm{T}} B_{\mathrm{T}}$ and $C_{\mathrm{SH}}=a_{\mathrm{SH}} B_{\mathrm{SH}}+a_{\mathrm{SH}^{2}} B_{\mathrm{SH}^{2}}$ (see Eq.(4)). Parenthesized values are individual contributions to $B_{\mathrm{m}}$. Asterisks and crosses indicate statistical significance at 0.05 and 0.1 levels, respectively.

and a mean error for DMHI top $10 \%$ showed $-0.5^{\circ} \mathrm{C}$ and $1.6^{\circ} \mathrm{C}$, respectively. The residual diagnostics of the final regression model (i.e., independent error, normality of error, homoscedasticity of error, and outlier leverage) [35] were visually inspected and found to be fair. In our trend estimation, a yearly series of a seasonal quantity was used, and each yearly value was formed as seasonal average (i.e., over daily values in a season). Its trend was assigned by the slope of the linear fit to the yearly series. Given the linearized expression in Eq. (4), the following equation applies:

$$
B_{\mathrm{m}}=a_{\mathrm{T}} B_{\mathrm{T}}+a_{\mathrm{SH}} B_{\mathrm{SH}}+a_{\mathrm{SH}^{2}} B_{\mathrm{SH}^{2}},
$$

where $B_{\mathrm{m}}, B_{\mathrm{T}}, B_{\mathrm{SH}}$, and $B_{\mathrm{SH}^{2}}$ are the slopes of linear fit to $\mathrm{DMHI}_{\mathrm{m}}, \mathrm{T}, \mathrm{SH}$, and $\mathrm{SH}^{2}$ terms, respectively. The total contribution of temperature to $B_{\mathrm{m}}\left(C_{\mathrm{T}}\right)$ equals $a_{\mathrm{T}} B_{\mathrm{T}}$ while that of humidity $\left(C_{\mathrm{SH}}\right)$ is given by $a_{\mathrm{SH}} B_{\mathrm{SH}}+a_{\mathrm{SH}^{2}} B_{\mathrm{SH}^{2}}$.

All the trend results are given in Fig. S5. DMHI and $\mathrm{DMHI}_{\mathrm{m}}$ trends in every case were compatible in direction and close in magnitude (within a margin of $30 \%$ ), reflecting the capability of the polynomial regression model to capture the original trends. In every city (except PP), the trends were positive (i.e., increasing), implying increased thermal discomfort, and their magnitudes in the wet season were larger than those in the dry season. In terms of trend magnitude (B), BK: $0.07^{\circ} \mathrm{C} \mathrm{dec}^{-1}$ (dry) and $0.26^{\circ} \mathrm{C} \mathrm{dec}^{-1}$ (wet), CM: $0.26^{\circ} \mathrm{C} \mathrm{dec}^{-1}$ (dry), and VT: $0.37^{\circ} \mathrm{C} \mathrm{dec}{ }^{-1}$ (wet). Nevertheless, the trends at $\mathrm{BK}$ and $\mathrm{CM}$ were not significant (at both the 0.05 and 0.1 levels). PP had the negative (i.e., decreasing) trends in both seasons, i.e., $-1.27^{\circ} \mathrm{C}$ $\mathrm{dec}^{-1}$ (dry) and $-1.26^{\circ} \mathrm{C} \mathrm{dec}^{-1}$ (wet), but only the dry-season trend was significant (at the 0.05 level). VT had the significant (at the 0.1 level) positive trends in both seasons, i.e., $1.31^{\circ} \mathrm{C} \mathrm{dec}^{-1}$ (dry) and $1.91^{\circ} \mathrm{C} \mathrm{dec}^{-1}$ (wet). For factor attribution (Table 1 ), trends at $\mathrm{BK}$ in both seasons were found to be more influenced by temperature whereas those at $\mathrm{CM}$ were temperature-dominated in the dry season but humidity-dominated in the wet season. At PP and VT, the trends in both seasons were humiditydominated. Long-term (1975-2017) trend estimation for annual mean $\mathrm{HI}$ at 74 sites across Thailand was studied [20] which reported positive trends in the majority of the sites, including those in the northern and central regions. Trends in temperature and relative humidity were also inspected and reasonable agreement of trend direction between $\mathrm{HI}$ and temperature was found.

Table 1 also shows the dry-season and wetseason $\mathrm{DMHI}_{\mathrm{m}} \mathrm{s}$. Trends at BK showed a relatively large differences, compared to the other cities, due to the large contrast between the two seasonal SH trends, indicating the influence of humidity. Likewise, the negative trends in $\mathrm{DMHI}_{\mathrm{m}}$ observed at PP in both seasons appeared to be regulated by the relatively large negative $\mathrm{SH}$ trends. Moreover, the results also showed no indication for $\mathrm{DMHI}_{\mathrm{m}}$ (i.e., mean) and DMHI_T10 m (i.e., extreme) trends to be 
directionally consistent, as seen at BK. Long-term temperature trends tended to be coherently positive due to global warming for both mean and extreme quantities, which may not be the case for precipitation. Since DMHI depends on both temperature and humidity, trends in its mean and extreme may not be straightforward as those in temperature. Although no clear or full explanation can be given to the above-mentioned results at BK and PP based on our current investigation (i.e., beyond the scope of this study), both are low-latitude cities and closer to the Gulf of Thailand, partly suggesting the potential role of their geographical locations to allow for humidity to influence or moderate trends more than those in high-latitude cities (CM and VT).

For trends in extreme conditions, they are essential in the context of climate change. Trend estimation was thus extended in the same fashion to seasonal DMHI extreme, defined as the average over high-end daily DMHI values (here, equal to or greater than the 90th percentile in a single season) and denoted by DMHI_T10 (Fig. S4). The trend direction of DMHI_T10 was the same as its previous DMHI counterpart, except for the opposite direction at BK. In terms of trend magnitude (B), BK: $-0.17^{\circ} \mathrm{C}$ $\operatorname{dec}^{-1}$ (dry) and $-0.19^{\circ} \mathrm{C} \mathrm{dec}^{-1}$ (wet), CM: $0.15^{\circ} \mathrm{C}$ $\operatorname{dec}^{-1}$ (dry) and $0.23^{\circ} \mathrm{C} \mathrm{dec}^{-1}$ (wet), PP: $-3.16^{\circ} \mathrm{C}$ $\mathrm{dec}^{-1}$ (dry) and $-2.28^{\circ} \mathrm{C} \mathrm{dec}{ }^{-1}$ (wet), VT: $2.4^{\circ} \mathrm{C}$ $\mathrm{dec}^{-1}$ (dry) and $2.92{ }^{\circ} \mathrm{C} \mathrm{dec}^{-1}$ (wet). For BK and $\mathrm{CM}$, trends were not significant in both seasons (at both the 0.05 and 0.1 levels). PP had only the dryseason trend being significant (at the 0.05 level), but VT had the trends in both seasons being significant (at the 0.1 level). As for factor attribution (Table 1), DMHI_T10 trends tended to be humiditydominated, as seen from almost all city and season cases (7 out of 8), except for the wet season at CM, which was more apparent than DMHI trends were.

Given the shorter period (i.e., 2001-2017) of data at PP and VT, trends at $\mathrm{BK}$ and $\mathrm{CM}$ were here recomputed over this period for the purpose of comparison, and a negative trend direction was coherently found among BK, CM, and PP with a larger magnitude in DMHI_T10 than that in DMHI in each of these three cities (Fig. S5). A contrast in the estimated trends using the full and shorter periods at BK and CM was also clearly seen. That is, using the more recent shorter period tends to subdue the trends toward being less positive or more negative. This highlights the effect of time coverage on the estimated trends.
Table 2 Partial correlations with lagged climate indices by season.

\begin{tabular}{|c|c|c|c|c|c|}
\hline \multirow{2}{*}{ City } & \multirow{2}{*}{ Variable } & \multicolumn{2}{|c|}{ Dry Season } & \multicolumn{2}{|c|}{ Wet Season } \\
\hline & & Nino3.4 & DMI & Nino3.4 & DMI \\
\hline \multirow{4}{*}{ BK } & DMHI & 0.25 & -0.11 & 0.22 & -0.15 \\
\hline & $\mathrm{T}$ & $0.53^{*}$ & 0.23 & $0.45^{*}$ & -0.01 \\
\hline & RH & -0.27 & -0.25 & -0.07 & -0.14 \\
\hline & $\mathrm{SH}$ & -0.04 & -0.13 & 0.12 & -0.19 \\
\hline \multirow{4}{*}{ CM } & DMHI & 0.07 & $0.32^{\dagger}$ & 0.28 & 0.05 \\
\hline & $\mathrm{T}$ & 0.14 & $0.44^{*}$ & $0.54^{\dagger}$ & 0.03 \\
\hline & $\mathrm{RH}$ & -0.21 & 0.07 & -0.08 & 0.07 \\
\hline & $\mathrm{SH}$ & -0.21 & 0.13 & 0.07 & 0.07 \\
\hline \multirow{4}{*}{ PP } & DMHI & 0.42 & -0.40 & $0.44^{\dagger}$ & 0.24 \\
\hline & $\mathrm{T}$ & $0.50^{\dagger}$ & 0.36 & 0.28 & 0.12 \\
\hline & RH & -0.23 & $-0.58^{*}$ & 0.08 & 0.05 \\
\hline & $\mathrm{SH}$ & -0.13 & $-0.44^{\dagger}$ & 0.16 & 0.09 \\
\hline \multirow{4}{*}{ VT } & DMHI & $0.55^{*}$ & 0.17 & $0.51^{*}$ & 0.23 \\
\hline & $\mathrm{T}$ & $0.54^{*}$ & 0.14 & $0.57^{*}$ & 0.01 \\
\hline & RH & -0.19 & 0.06 & $-0.60 *$ & 0.33 \\
\hline & $\mathrm{SH}$ & 0.35 & 0.23 & 0.21 & $0.48^{\dagger}$ \\
\hline
\end{tabular}

Asterisks and crosses indicate statistical significance at 0.05 and 0.1 levels, respectively.

\section{Large-scale climatic influence}

In Southeast Asia, El Niño-Southern Oscillation (ENSO) and the Indian Ocean Dipole (IOD) are large-scale climatic modes that exert influences on climate variability, particularly at an inter-annual or year-to-year scales $[36,37]$. The ENSO typically has three phases (La Niña or cool, normal, and El Niño or warm), as identified by the negative, (near) zero, and positive anomalies of sea surface temperature (SST) in the Tropical Pacific, respectively. In relative terms, El Niño causes warm and dry (with less precipitation) conditions, while La Niña causes cool and moist (with more precipitation) conditions in Upper Southeast Asia [38], which is governed by certain physical mechanisms related to the zonal displacement of Walker circulation. Nino3.4, a standard ENSO index, was employed here to identify the strength and phase of ENSO. For IOD, it is the periodic oscillation of SST in the Indian Ocean, which similarly has two main phases (positive and negative) [39] that can be identified using the dipole mode index (DMI). Wet or dry and warm or cool tendencies due to IOD for the Eastern Indian Ocean, which is next to Upper Southeast Asia, are generally similar to ENSO. Given the spatial proximity of Upper Southeast Asia to both the Pacific and the Indian Ocean, both climatic modes are relevant. The very 
strong El Niño in 2015/2016 caused an extended extreme heat event in Thailand and its vicinity [40].

This study examined the general association of heat index with ENSO and IOD using partial correlation analysis. Partial correlation measures the association between a quantity of interest and a controlling variable excluding the effects of other controlling variables if any. Here, Nino3.4 and DMI are the controlling variables, of which the monthly data were obtained from the US National Oceanic and Atmospheric Administration (NOAA) (https://psl.noaa.gov, accessed on 5 June 2020). Firstly, the lag-correlation relationship was explored to determine an optimal time lag for each individual index by season for each city. Monthly Nino3.4 and DMI were first 6-month-running averaged, similar to [36]. The correlation between them (i.e., Nino3.4 and DMI) and seasonal DMHI average were assessed with varying time lag $(0,1,2, \ldots$ up to 6 months) as shown in Fig. S6. The optimal lag to be selected is the lag that gives the maximum or relatively high correlation in magnitude without many changes ( $<$ 0.01) afterwards. Across the cities, the optimal lag ranged from 0 to 3 months for Nino3.4, and from 0 to 5 months for DMI. Partial correlations between seasonal DMHI, T, and SH with lagged Nino3.4 and DMI were subsequently computed. With Nino3.4, DMHI was positively correlated in all cases of city and season (0.07-0.55), and so was T (0.14-0.57), but no correlation pattern was coherently seen for SH. DMHI had no conclusive direction for correlation with DMI (Table 2). Overall, based on the magnitude of partial correlation, it is possible to say that ENSO tends to exert more influence on DMHI than DMI does. ENSO correlation results agree with those of another study in Thailand [20] in which year-to-year variability in heat index is associated with ENSO. The effect of ENSO on interannual temperature variability and its extreme events in Thailand was also reported [38].

\section{CONCLUSION}

Ambient thermal comfort was analyzed using a standard heat index (HI) for Bangkok, Chiang Mai, Phnom Penh, and Vientiane, with data covering 37 and 17 years for the first two and last two cities, respectively. The key findings are summarized as follows: (1) HI diurnality tended to be more influenced by temperature than by relative humidity, with $\mathrm{HI}$ being relatively low during the night and the early morning, but high in the afternoon. (2) The daily maximum heat index (DMHI) was the most intensified in April-May due to the warm humid con- ditions and the lowest in mid-winter (DecemberJanuary) due to the cool dry air. (3) Among the five considered DMHI risk levels, "extreme caution" occurred the most often for the majority of the months, and "danger" occurrence tended to increase in the summer and early wet-season months (AprilJune). (4) HI was affected by geographical location with less pronounced diurnality and seasonality in the low-latitude cities (i.e., Bangkok and Phnom Penh) due to their proximity to the Equator and to large water bodies. (5) In both dry and wet seasons, increasing trends in seasonal DMHI average were found in all cities (except Phnom Penh), and increasing trends in seasonal DMHI extreme were found in Chiang Mai and Vientiane. These suggest concern and severity. (6) Most trends were more influenced by humidity than by temperature, based on our factor attribution. (7) ENSO had positive association with seasonal DMHI average and tended to show more influence than IOD did. The trends results offer perspectives for climate-related urban planning. The current analysis may be extended to the following aspects: spatial variability, including more cities, the roles of synoptic patterns, projected climate change, inter-annual variability, interaction between teleconnections, health risk, and linkage to urban-scale sustainability.

\section{Appendix A. Supplementary data}

The supplementary materials associated with this article can be found at http://dx.doi.org/10.2306/ scienceasia1513-1874.2021.067.

Acknowledgements: The authors thank the Thai Meteorological Department (Thailand), the Ministry of Water Resources and Meteorology (Cambodia), the Department of Meteorology and Hydrology (Laos), and the National Centers for Environmental Information (US) for the observed weather data. We thank Dr. Atsamon Limsakul, Dr. Sebastien Bonnet, and the anonymous reviewer for their useful comments and suggestions. This study was financially supported by the Joint Graduate School of Energy and Environment and the Postgraduate Education and Research Development Office, and the National Research Council of Thailand.

\section{REFERENCES}

1. Anderson GB, Bell ML, Peng RD (2013) Methods to calculate the heat index as an exposure metric in environmental health research. Environ Health Perspect 121, 1111-1119.

2. Binarti F, Koerniawan MD, Triyadi S, Sesotya S, Matzarakis A (2020) A review of outdoor thermal 
comfort indices and neutral ranges for hot-humid regions. Urban Clim 31, ID 100531.

3. Ramirez-Beltran ND, Gonzalez JE, Castro JM, Angeles M, Harmsen EW, Salazar CM (2017) Analysis of the heat index in the Mesoamerica and Caribbean region. J Appl Meteorol Climatol 56, 2905-2925.

4. NWS (2020) The heat index calculation. National Oceanic and Atmospheric Administration, National Weather Service. Available at: https://www.wpc. ncep.noaa.gov/html/heatindex_equation.shtml. [Accessed 25 Nov 2020].

5. Kamma J, Manomaiphiboon K, Aman N, Thongkamdee T, Chuangchote S, Bonnet S (2020) Urban heat island analysis for Bangkok: multi-scale temporal variation, associated factors, directional dependence, and cool island condition. ScienceAsia 46, 213-223.

6. Roth M (2007) Review of urban climate research in (sub)tropical regions. Int J Climatol 27, 1859-1873.

7. Yang W, Zhang G (2008) Thermal comfort in naturally ventilated and air-conditioned buildings in humid subtropical climate zone in China. Int J Biometeorol 52, 385-398.

8. Kjellstrom T, Kovats RS, Lloyd SJ, Holt T, Tol RSJ (2009) The direct impact of climate change on regional labor productivity. Arch Environ Occup Health 64, 217-227.

9. Dixon RW (1998) A heat index climatology for the southern United States. Natl Weather Dig 22, 16-21.

10. Hass AL, Ellis KN, Mason LR, Hathaway JM, Howe DA (2016) Heat and humidity in the city: Neighborhood heat index variability in a mid-sized city in the southeastern United States. Int J Environ Res Public Health 13, ID 117.

11. Founda D, Pierros F, Katavoutas G, Keramitsoglou I (2019) Observed trends in thermal stress at European cities with different background climates. Atmosphere 10, ID 436.

12. Desai MS, Dhorde AG (2018) Trends in thermal discomfort indices over western coastal cities of India. Theor Appl Climatol 131, 1305-1321.

13. Delworth TL, Mahlman JD, Knutson TR (1999) Changes in heat index associated with $\mathrm{CO}_{2}$-induced global warming. Clim Change 43, 369-386.

14. Amatayakul P (2006) Estimating Heat Index Value using Steadman's Method, Technical Document No. 551.551-33-01-2006, Thai Meteorological Department, Thailand. [in Thai]

15. Langkulsen U, Vichit-Vadakan N, Taptagaporn S (2010) Health impact of climate change on occupational health and productivity in Thailand. Glob Health Action 3, ID 5607.

16. Opitz-Stapleton S, Sabbag L, Hawley K, Tran P, Hoang L, Nguyen PH (2016) Heat index trends and climate change implications for occupational heat exposure in Da Nang, Vietnam. Clim Serv 2-3, 41-51.

17. Thawillarp S, Thammawijaya P, Praekunnatham $H$,
Siriruttanapruk S (2015) Situation of heat-related illness in Thailand, and the proposing of heat warning system. OSIR $J$ 8, 15-23.

18. Phunthirawuthi P, Saengrattanayon C, Kirtsaeng S (2019) Heat illness related meteorology over Chiang Mai using automatic weather station observed data. Appl Mech Mater 891, 142-148.

19. Srivanit M, Auttarat S (2015) The summer thermal environment and human comfort of shaded outdoor and semi-outdoor spaces to living in the urban area of Chiang Mai city. J Archit Res Stud 12, 53-72.

20. Paengkaew W, Limsakul A, Junggoth R, Pitaksanurat $S$ (2020) Variability and trend of heat index in Thailand during 1975-2017 and their relationships with some demographic-health variables. EnvironmentAsia 13, 26-40.

21. Torsri K, Octaviani M, Manomaiphiboon K, Towprayoon S (2013) Regional mean and variability characteristics of temperature and precipitation over Thailand in 1961-2000 by a regional climate model and their evaluation. Theor Appl Climatol 113, 289-304.

22. Rodell M, Houser PR, Jambor UEA, Gottschalck J, Mitchell K, Meng CJ, Arsenault K, Cosgrove B, et al (2004) The global land data assimilation system. Bull Amer Meteor Soc 85, 381-394.

23. Stewart ID, Oke TR (2012) Local climate zones for urban temperature studies. Bull Amer Meteor Soc 93, 1880-1900.

24. Kalnay E, Cai M (2013) Impact of urbanization and land-use change on climate. Nature 423, 528-531.

25. Aman N, Manomaiphiboon K, Pengchai P, Suwanathada P, Srichawana J, Assareh N (2019) Long-term observed visibility in Eastern Thailand: temporal variation, association with air pollutants and meteorological factors, and trends. Atmosphere 10, ID 122.

26. Yue S, Pilon P (2004) A comparison of the power of the $t$-test, Mann- Kendall and bootstrap tests for trend detection. Hydrol Sci J 49, 21-37.

27. Reeves J, Chen J, Wang XL, Lund R, Lu QQ (2007) A review and comparison of changepoint detection techniques for climate data. $J$ Appl Meteorol Climatol 46, 900-915.

28. Ross GJ (2015) Parametric and nonparametric sequential change detection in R: the cpm package. $J$ Stat Softw 66, 1-20.

29. Steadman RG (1979) The assessment of sultriness. Part I: A temperature-humidity index based on human physiology and clothing science. J Appl Meteorol 18, 861-873.

30. Steadman RG (1984) A universal scale of apparent temperature. J Clim Appl Meteorol 23, 1674-1687.

31. Rothfusz LP (1990) The Heat Index Equation, Technical Attachment No. SR 90-23, National Weather Service.

32. Dahl K, Licker R, Abatzoglou JT, Declet-Barreto J (2019) Increased frequency of and population expo- 
sure to extreme heat index days in the United States during the 21st century. Environ Res Commun 1, ID 075002 .

33. Weinberger KR, Zanobetti A, Schwartz J, Wellenius GA (2018) Effectiveness of national weather service heat alerts in preventing mortality in 20 US cities. Environ Int 116, 30-38.

34. Walsh RPD, Lawler DM (1981) Rainfall seasonality: Decription, spatial patterns and change through time. Weather 36, 201-208.

35. Wilks DS (2006) Statistical Methods in the Atmospheric Sciences, Academic Press, California, USA.

36. Hendrawan IG, Asai K, Triwahyuni A, Lestari DV (2019) The interanual rainfall variability in Indonesia corresponding to El Niño Southern Oscillation and Indian Ocean Dipole. Acta Oceanol Sin 38, 57-66.

37. Yeh SW, Cai W, Min SK, McPhaden MJ, Dommenget D, Dewitte B, Collins M, Ashok K, et al (2018) ENSO atmospheric teleconnections and their response to greenhouse gas forcing. Rev Geophys 56, 185-206.

38. Limsakul A, Goes JI (2008) Empirical evidence for interannual and longer period variability in Thailand surface air temperatures. Atmos Res 87, 89-102.

39. Bridhikitti A (2019) Multi-decadal trends and oscillations of southeast asian monsoon rainfall in northern thailand. Songklanakarin J Sci Technol 41, 74-80.

40. Christidis N, Manomaiphiboon K, Ciavarella A, Stott PA (2018) The hot and dry April of 2016 in Thailand. Bull Am Meteorol Soc 99, S128-S132. 


\section{Appendix A. Supplementary data}

Table S1 Weather stations considered in the study.

\begin{tabular}{|c|c|c|c|c|c|c|c|}
\hline City & $\begin{array}{l}\text { WMO } \\
\text { Code }\end{array}$ & $\begin{array}{l}\text { Lat. } \\
\text { (deg) }\end{array}$ & $\begin{array}{l}\text { Long. } \\
\text { (deg) }\end{array}$ & $\begin{array}{l}\text { Elevation } \\
(\mathrm{m} \text { msl) }\end{array}$ & Period & Variables & $\begin{array}{c}\text { Total days } \\
\text { (\% computable DMHI) }\end{array}$ \\
\hline $\begin{array}{l}\text { Bangkok (BK) } \\
\text { Thailand }\end{array}$ & 484560 & 13.909 & 100.596 & 9 & $\begin{array}{l}\text { Nov. } 1980 \text { to Oct. } 2017 \\
\text { (37 years) }\end{array}$ & \multirow{4}{*}{$\mathrm{T}, \mathrm{RH}, \mathrm{P}$} & $\begin{array}{l}\text { Dry: } 6,706(93.5 \%) \\
\text { Wet: } 6,808(94.3 \%)\end{array}$ \\
\hline $\begin{array}{l}\text { Chiang Mai (CM) } \\
\text { Thailand }\end{array}$ & 483270 & 18.771 & 98.973 & 308 & $\begin{array}{l}\text { Nov. } 1980 \text { to Oct. } 2017 \\
\text { (37 years) }\end{array}$ & & $\begin{array}{l}\text { Dry: } 6,706(96.7 \%) \\
\text { Wet: } 6,808(96.0 \%)\end{array}$ \\
\hline $\begin{array}{l}\text { Phnom Penh (PP) } \\
\text { Cambodia }\end{array}$ & 489910 & 11.560 & 104.850 & 15 & $\begin{array}{c}\text { Nov. } 2000 \text { to Oct. } 2017 \\
\text { (17 years) }\end{array}$ & & $\begin{array}{l}\text { Dry: 3,081 (96.5\%) } \\
\text { Wet: 3,128 (95.7) }\end{array}$ \\
\hline $\begin{array}{l}\text { Vientiane (VT) } \\
\text { Laos }\end{array}$ & 489400 & 17.987 & 102.563 & 170 & $\begin{array}{c}\text { Nov. } 2000 \text { to Oct. } 2017 \\
\text { (17 years) }\end{array}$ & & $\begin{array}{l}\text { Dry: 3,081 }(96.1 \%) \\
\text { Wet: 3,128 }(94.5 \%)\end{array}$ \\
\hline
\end{tabular}

All stations are airport-based and WMO-registered. T is hourly near-surface air temperature $\left({ }^{\circ} \mathrm{C}\right)$. $\mathrm{RH}$ is hourly nearsurface relative humidity (\%). P is 3-hourly surface pressure (Pa) from GLDAS, then linearly interpolated to hourly values.

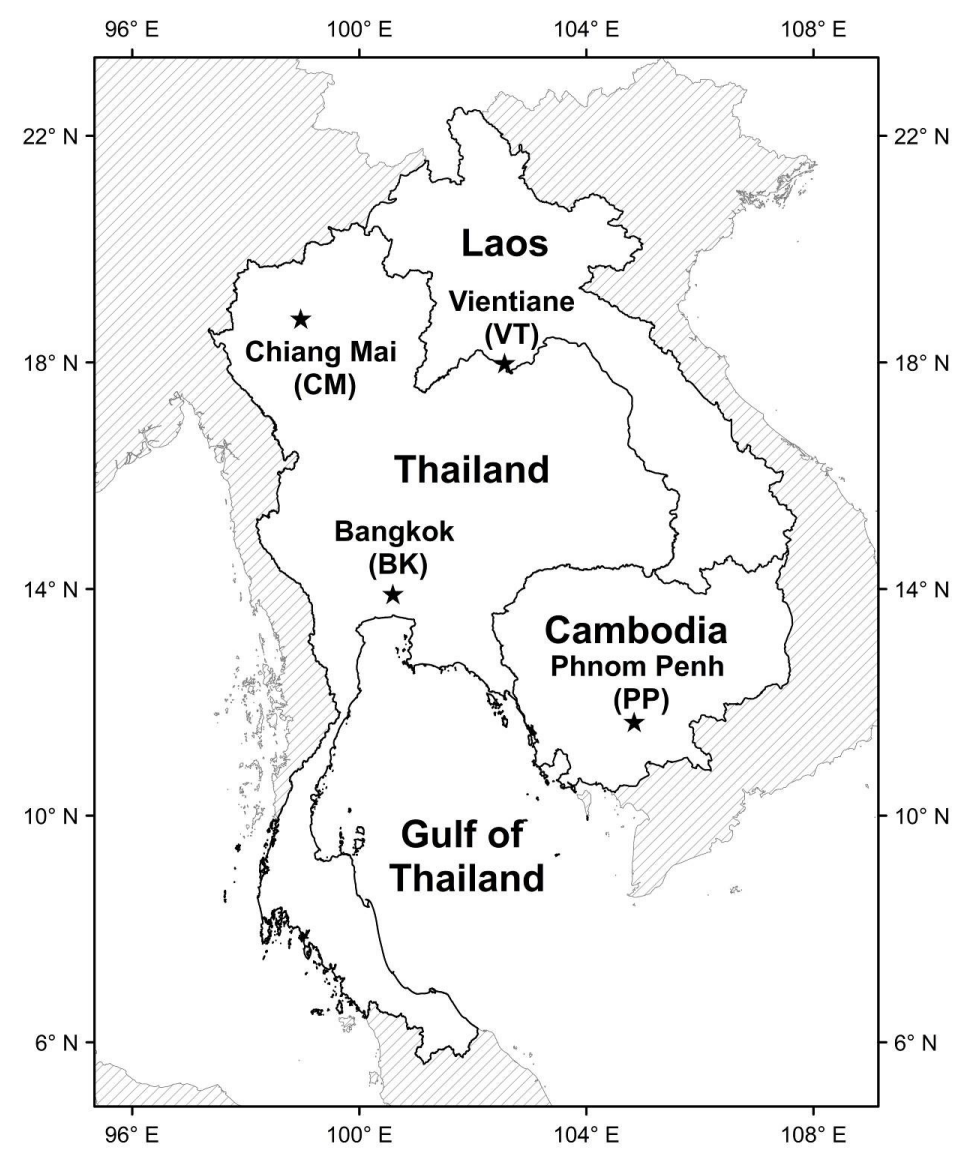

Fig. S1 Map of Thailand, Cambodia, and Laos, showing the four selected weather stations (marked by black-filled stars). 

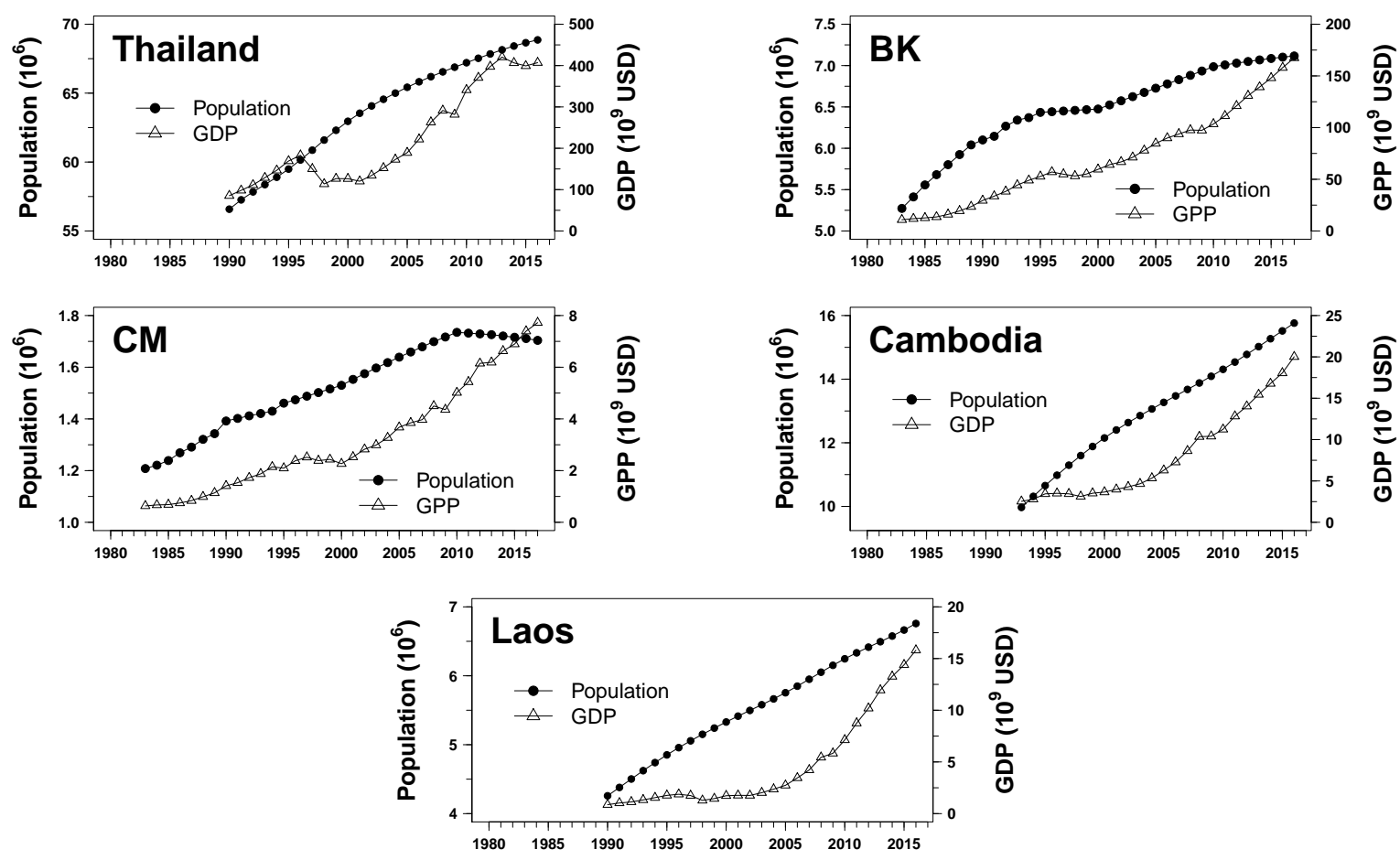

Fig. S2 Population (registered) and gross domestic/provincial product (GDP/GPP) for Thailand, Bangkok, Chiang Mai, Cambodia, and Laos. GDP is an aggregate index used to indicate the productivity of total economic activities for a nation. In Thailand, gross provincial product (GPP) was estimated for individual provinces (here, Bangkok and Chiang Mai). GPP has the same definition as that of GDP but scaled to a provincial level instead. GDP values are from the World Bank (https://data.worldbank.org/country, accessed on 7 November 2018). The GPP values are available at https://www.nesdb.go.th/main.php?filename=gross_regional (accessed on 7 August 2017). The acronym USD is short for US dollar. 


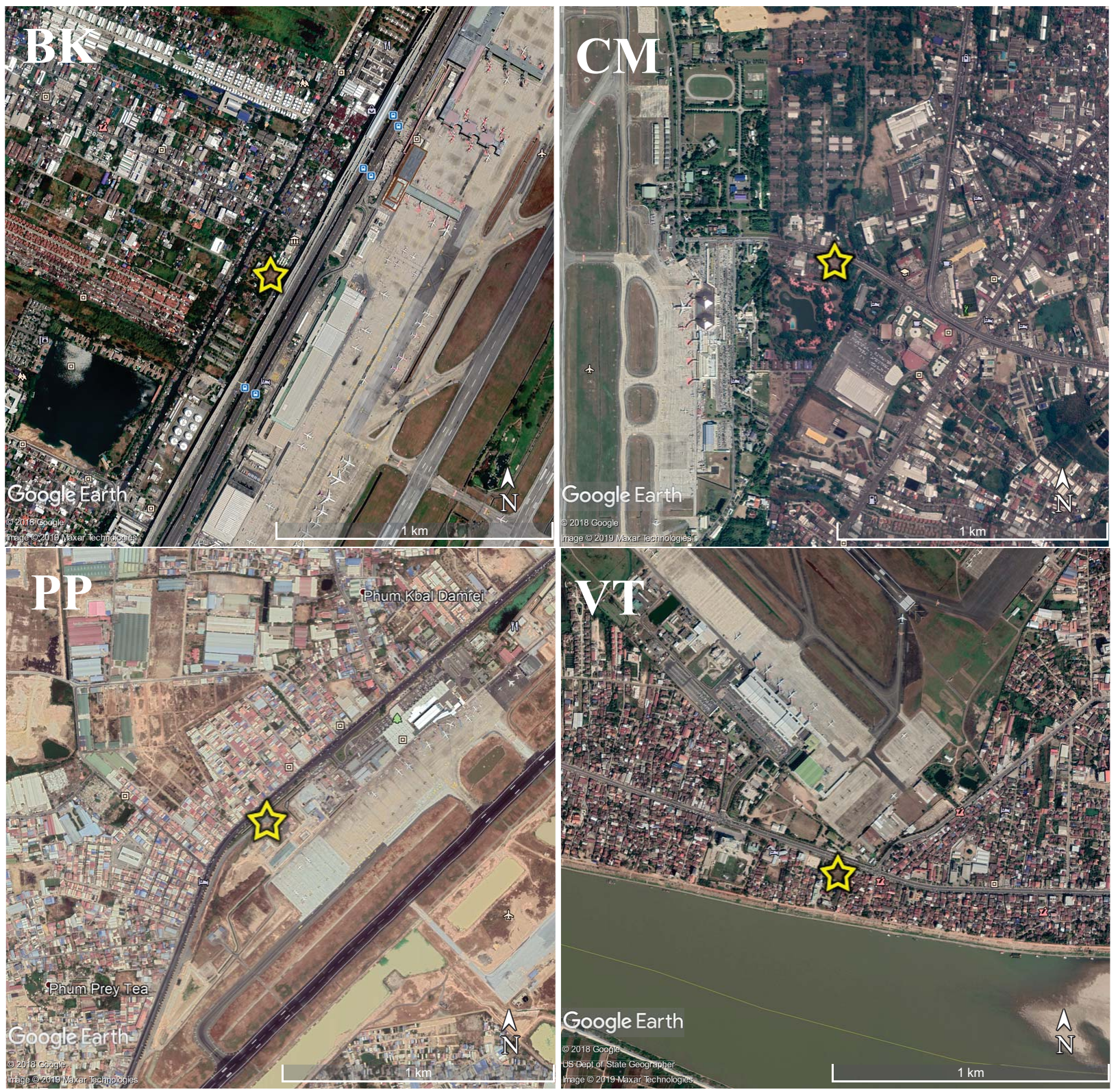

Fig. S3 Surrounding area (2-km radius or $4 \times 4 \mathrm{~km})$ of each weather station (marked by a yellow star), taken from Google Earth. 


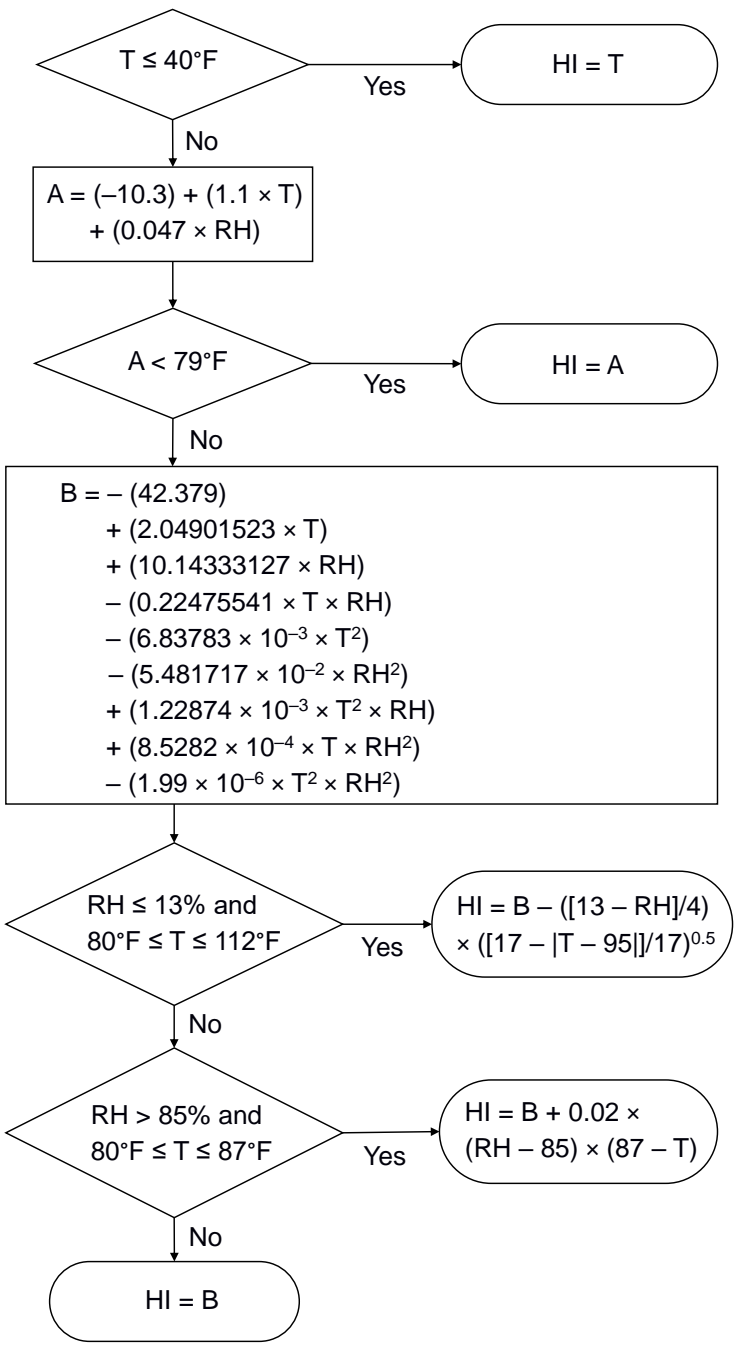

Fig. S4 Heat index (HI) calculation used by US National Weather Service (NWS). $\mathrm{T}$ is in ${ }^{\circ} \mathrm{F}$, and $\mathrm{RH}$ is in percentage. 
(a) BK (1981-2017)

(a1) DMHI in dry season

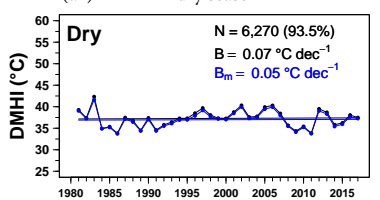

(b) BK (2001-2017)

(b1) DMHI in dry season

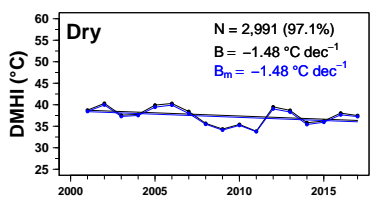

(c) CM (1981-2017)

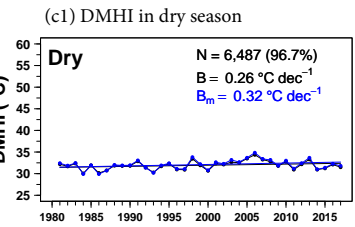

(d) CM (2001-2017)

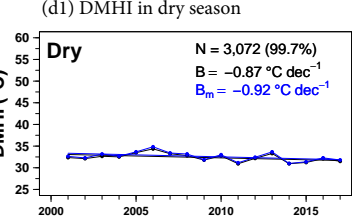

(e) PP (2001-2017)

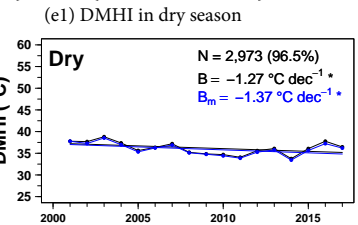

(f) VT (2001-2017)

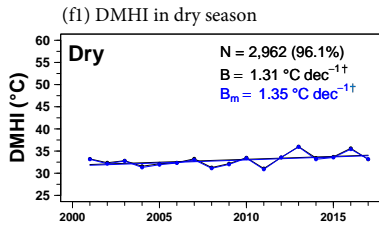

(a2) DMHI_T10 in dry seaon

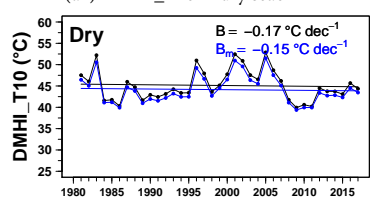

(b2) DMHI_T10 in dry season

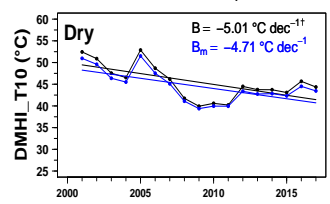

(c2) DMHI_T10 in dry season

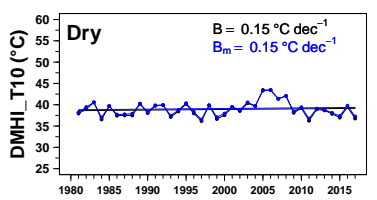

(d2) DMHI_T10 in dry seaon

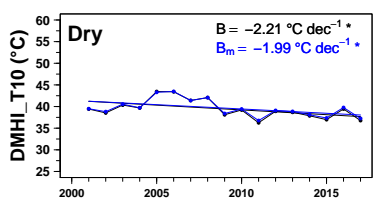

(e2) DMHI_T10 in dry seaon

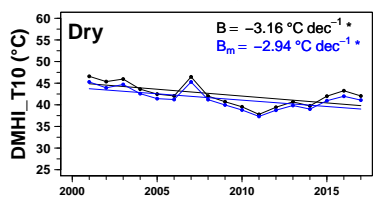

(f2) DMHI_T10 in dry seaon

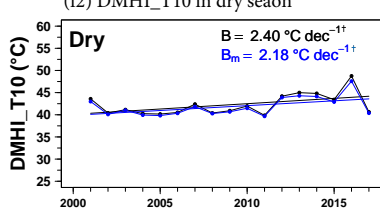

(a3) DMHI in wet season

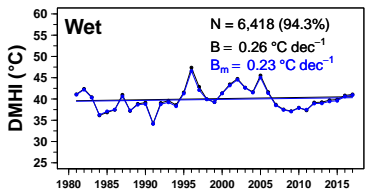

(b3) DMHI in wet season

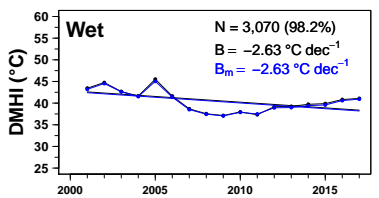

(c3) DMHI in wet season

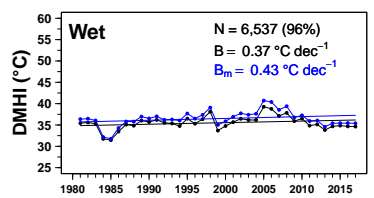

(d3) DMHI in wet season

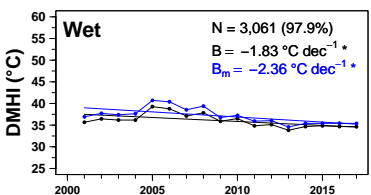

(e3) DMHI in wet season

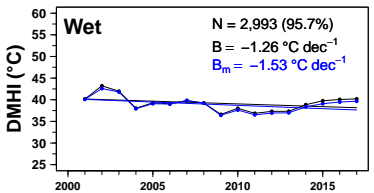

(f3) DMHI in wet season

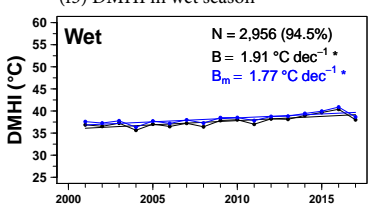

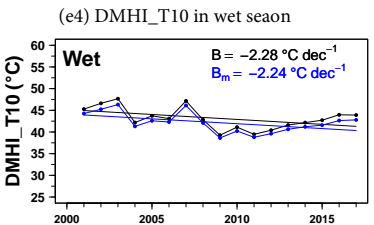

(a4) DMHI_T10 in wet seaon

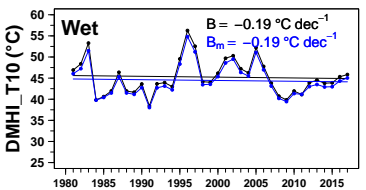

(b4) DMHI_T10 in wet seaon

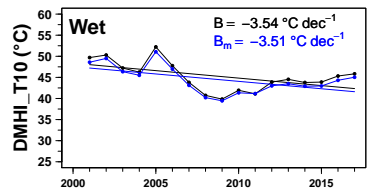

(c4) DMHI_T10 in wet seaon

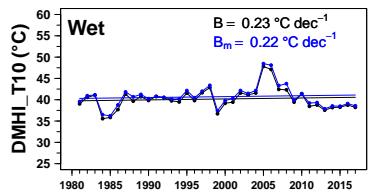

(d4) DMHI_T10 in wet seaon

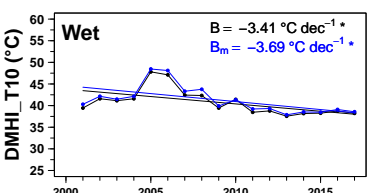

(f4) DMHI_T10 in wet seaon

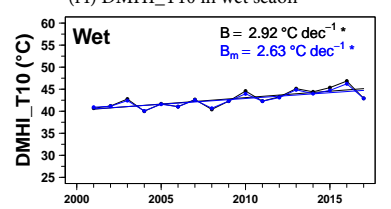

Fig. S5 Trends in original DMHI and DMHI_T10 (B), and trends in $\mathrm{DMHI}_{\mathrm{m}}$ and DMHI_T10 ${ }_{\mathrm{m}}\left(B_{m}\right)$ by season and city: (a) BK (1981-2017), (b) BK (2001-2017), (c) CM (1981-2017), (d) CM (2001-2017), (e) PP (2001-2017), and f) VT (2001-2017). Parenthesized numbers are of seasonal year. Single asterisk and cross sign indicate statistical significance at 0.05 and 0.1 levels, respectively. $N$ is total number of daily values used in trend estimation. 

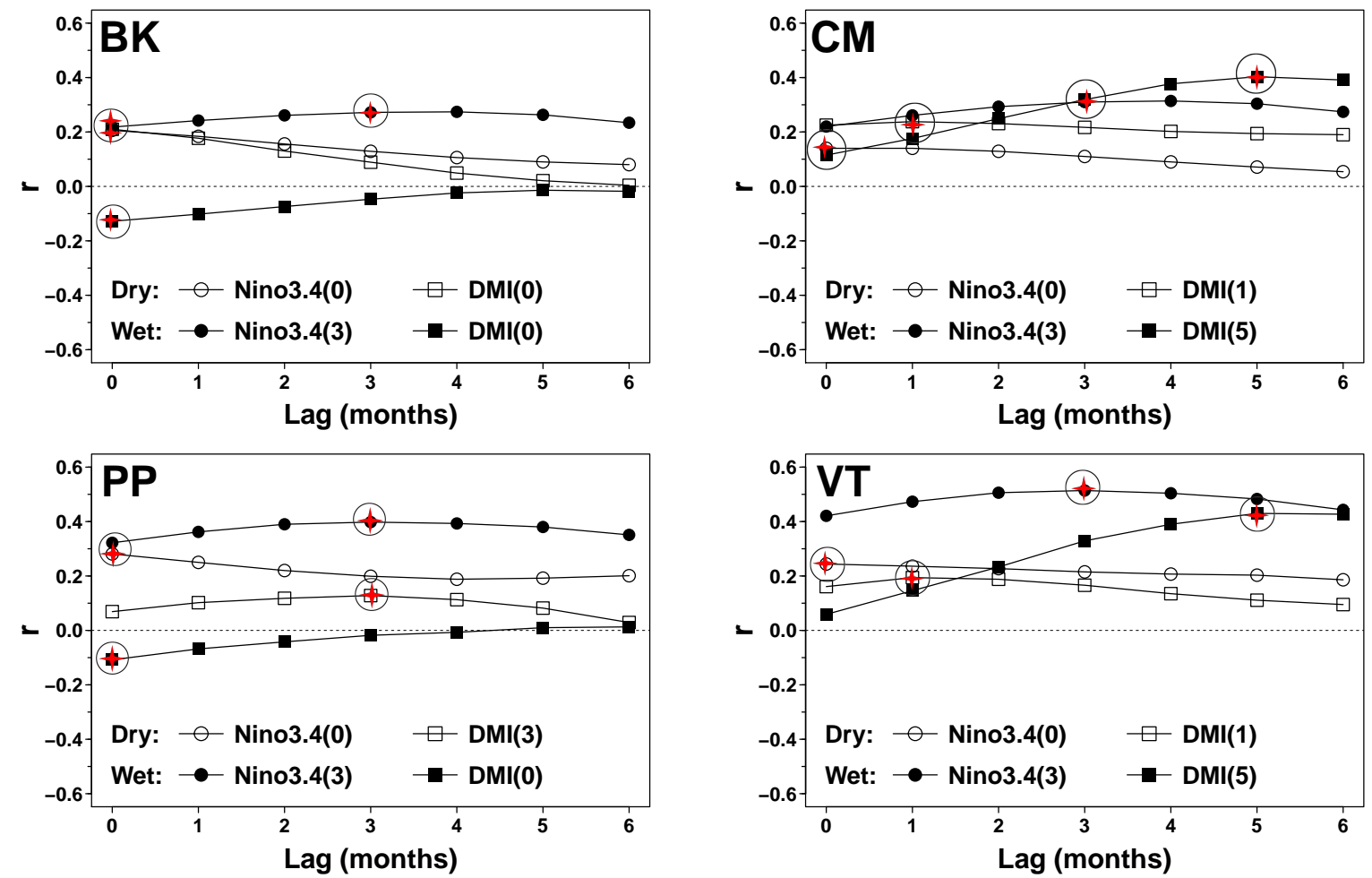

Fig. S6 Time lag and correlation between DMHI and climatic index (Nino3.4 or DMI) by season. Circled points and parenthesized numbers mark optimal lags. 